\title{
Huzita-Justin vs. Alperin-Lang: Solusi Persamaan Kubik Dengan Konstruksi Origami
}

\author{
Huzita-Justin vs. Alperin-Lang: Solution of Cubic Equation using Origami Construction
}

\author{
Respitawulan \\ Program Studi Matematika, FMIPA, Universitas Islam Bandung \\ respitawulan@unisba.ac.id
}

\begin{abstract}
Abstrak. Dalam artikel ini, dilihat aplikasi origami dalam mencari solusi dari persamaan kubik. Pencarian solusi dari persamaan kubik dilakukan melalui konstruksi origami. Terdapat dua macam konstruksi origami yang telah dikenal luas: konstruksi dari Huzita-Justin dan Alperin-Lang. Dari perbandingan kedua konstruksi tersebut untuk menyelesaikan persamaan kubik, terlihat bahwa Huzita-Justin memberikan langkah yang lebih sederhana dalam pencarian solusi persamaan kubik, tetapi Alperin-Lang lebih powerful karena dapat dipergunakan untuk menyelesaikan persamaan polinom dengan derajat lebih tinggi.
\end{abstract}

Kata kunci: solusi persamaan kubik, konstruksi origami, metoda Lill

Abstract. In this article, we see the application of origami to find the solution of cubic equation. There are two well-known origami constructions: Huzita-Justin's and Alperin-Lang's construction. Comparing both constructions to solve cubic equation, Huzita-Justin's gives simpler steps. Although, Alperin-Lang's is more powerful since it can be used to solve equations with higher degree.

Keywords: cubic equation solution, origami construction, Lill's method

\section{Pendahuluan}

Origami telah banyak dipelajari dalam kaitannya dengan Matematika, mulai dari kaitannya dengan geometri (bangun datar, bangun ruang, sudut) [1], kombinatorika (graf, fraktal, pengubinan) [2], hingga aljabar dan analisis [3]. Dalam hal pembelajaran Matematika, origami juga dapat dimanfaatkan pada berbagai tingkatan pendidikan, mulai dari usia dini [4], tingkat SD [[5],[6],[7],[8]] dan SMP [[9],[10]]. Origami juga dapat membantu meningkatkan kecerdasan spasial dan kemampuan berpikir kreatif siswa [11]. Pembelajaran dengan origami telah menjadi alternatif sarana pembelajaran Matematika lain seperti multimedia [12] atau software [13].

Salah satu aspek dalam origami yang sering diteliti adalah yang berkaitan dengan pola bekas lipatan atau crease pattern. Dalam kaitannya dengan persamaan polinom, konstruksi crease pattern origami ini pertama kali dipergunakan oleh Beloch pada 1936 untuk mencari solusi persamaan kubik [14]. Namun, sejak saat itu cara konstruksi origami telah mengalami perkembangan. Berbagai versi untuk melakukan konstruksi origami pun muncul. Di sini, dibahas mengenai dua versi konstruksi origami: konstruksi Huzita-Justin dan Operasi Multi-Lipatan Alperin-Lang. Kedua metode konstruksi tersebut selanjutnya dipergunakan untuk mencari solusi persamaan kubik serta perbandingan keduanya.

\section{Konstruksi Origami}

\subsection{Konstruksi Origami Huzita-Justin}

Konstruksi origami dari Huzita-Justin (juga dikenal sebagai konstruksi Huzita-Hattori) adalah konstruksi origami yang pertama kali dikenal. Konstruksi ini merupakan konstruksi origami yang paling banyak dipergunakan. Terdapat enam operasi yang diberikan oleh Huzita dan satu operasi yang 
diberikan oleh Justin. Ketujuh operasi ini memberikan konstruksi yang 'lengkap' untuk origami satu lipatan, dalam artian tidak ada lagi operasi lain yang dapat dibuat melainkan sebagai variasi dari operasi-operasi ini [15]. Gambar 1 memberikan contoh lipatan yang dibentuk oleh konstruksi HuzitaJustin. Berikut ini diberikan masing-masing operasi dari konstruksi origami Huzita-Justin.

Operasi 1 Huzita-Justin (O1): Jika terdapat dua titik P dan Q, maka terdapat garis lipatan $L_{f}$ yang melalui titik P dan Q.

Garis lipatan $L_{f}$ adalah garis lurus yang melalui kedua titik P dan Q sekaligus. Garis lipatan ini selalu ada meskipun tidak selalu tunggal.

Operasi 2 Huzita-Justin (O2): Jika terdapat dua titik P dan Q, maka terdapat garis lipatan $L_{f}$ yang membuat titik $\mathrm{P}$ dan $\mathrm{Q}$ berimpit.

Garis lipatan $L_{f}$ adalah garis yang tegak lurus dengan segmen garis PQ dan melalui titik tengah segmen PQ. Garis lipatan ini selalu ada meskipun tidak selalu tunggal.

Operasi 3 Huzita-Justin (O3): Jika terdapat dua garis $m$ dan n, maka terdapat garis lipatan $L_{f}$ yang membuat $m$ dan $n$ berimpit.

Operasi 4 Huzita-Justin (O4): Jika terdapat satu buah titik $\mathrm{P}$ dan satu buah garis $\mathrm{m}$, maka terdapat garis lipatan $L_{f}$ yang tegak lurus $\mathrm{m}$ dan melalui $\mathrm{P}$.

Operasi 5 Huzita-Justin (O5): Jika terdapat dua buah titik $P$ dan Q serta satu buah garis $\mathrm{m}$, maka terdapat garis lipatan $L_{f}$ yang membawa $\mathrm{P}$ ke $\mathrm{m}$ dan melalui Q.

Operasi 6 Huzita-Justin (O6): Jika terdapat dua buah titik P dan Q serta dua buah garis $\mathrm{m}$ dan $\mathrm{n}$, maka terdapat garis lipatan $L_{f}$ yang membawa titik $\mathrm{P}$ ke garis $\mathrm{m}$ dan titik $\mathrm{Q}$ ke garis $\mathrm{n}$ secara bersamaan.

Operasi 7 Huzita-Justin (O7): Jika terdapat satu titik P serta dua buah garis $\mathrm{m}$ dan n, maka terdapat garis lipatan $L_{f}$ yang tegak lurus dengan garis $\mathrm{n}$ dan membawa titik $\mathrm{P}$ ke garis $\mathrm{m}$.
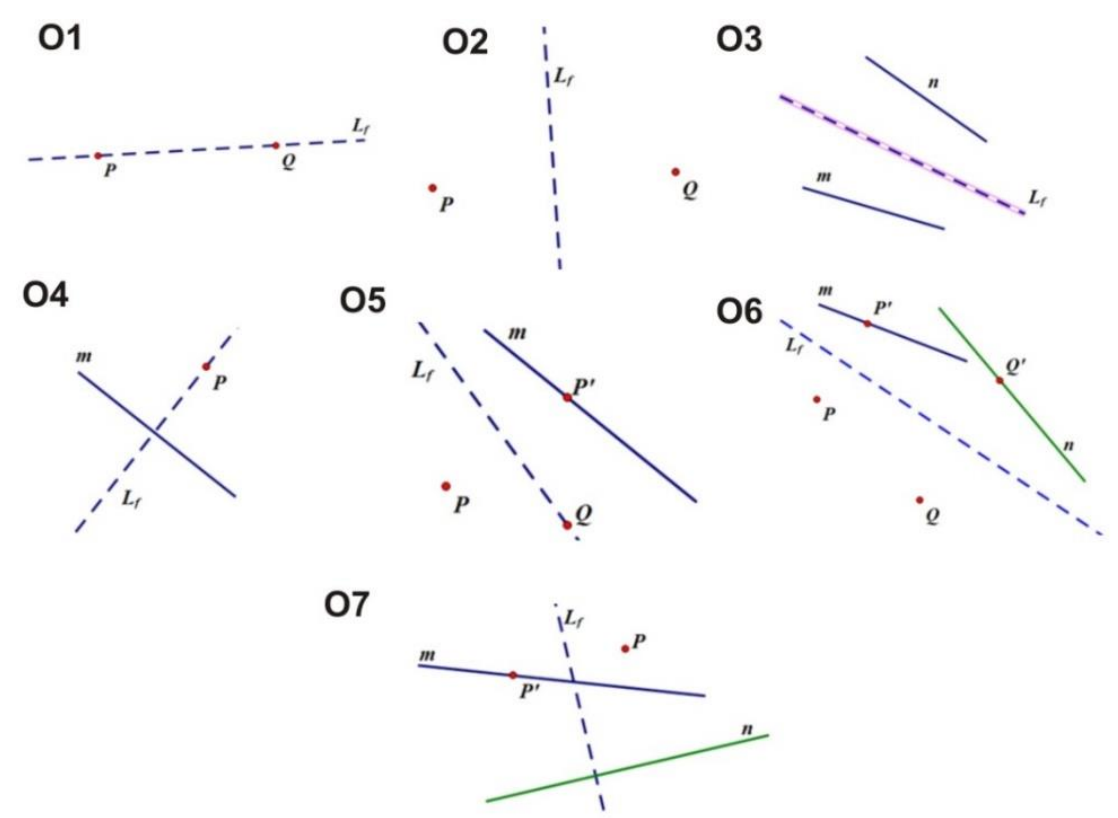

Gambar 1 Konstruksi Origami dengan Operasi Huzita-Justin 


\subsection{Konstruksi Origami Alperin-Lang}

Untuk membahas konstruksi origami dari Alperin-Lang [16], terlebih dahulu diperlukan beberapa definisi sebagai berikut.

\section{Definisi (Titik Hasil Lipatan)}

Peta hasil lipatan $f_{L_{f}}(P)$ dari titik $P$ akibat garis lipatan $L_{f}$ adalah hasil refleksi titik $P$ terhadap garis $L_{f}$.

\section{Definisi (Garis hasil lipatan)}

Peta hasil lipatan $f_{L_{f}}(m)$ dari garis $m$ akibat garis lipatan $L_{f}$ adalah hasil refleksi garis $m$ terhadap garis $L_{f}$.

Dari sifat refleksi, diketahui bahwa dua refleksi berturut-turut terhadap sebuah garis merupakan suatu pemetaan identitas, artinya objek yang direfleksikan tidak berpindah. Jika terdapat dua objek A dan B, maka terdapat garis lipatan $L_{f}$ yang membawa A ke B. Dengan menggunakan sifat refleksi tersebut, dapat dengan mudah terlihat bahwa

$$
\mathrm{f}_{\mathrm{Lf}_{\mathrm{f}}}(\mathrm{A})=\mathrm{B} \Leftrightarrow \mathrm{f}_{\mathrm{L}_{\mathrm{f}}}(\mathrm{B})=\mathrm{A} \text {. }
$$

Pada dasarnya, dalam origami, garis lipatan dikonstruksi saat satu titik atau garis dibawa ke satu titik atau garis lain sehingga keduanya menjadi berimpit "aligned". Jika terdapat dua objek, A dan B, yang berimpit, maka keterimpitan "alignment" antara kedua objek tersebut dinotasikan dengan $A \leftrightarrow B$. Terdapat tiga jenis keterimpitan yang mungkin terjadi dalam origami, yaitu:

1. Keterimpitan Titik ke Titik

Misalkan $\mathrm{P}$ dan $\mathrm{Q}$ sebarang titik, $P \leftrightarrow Q$ jika dan hanya jika $P=Q$.

2. Keterimpitan Garis ke Garis

Misalkan 1 dan m sebarang garis, $l \leftrightarrow m$ jika dan hanya jika untuk $P_{1}, P_{2} \in l, P_{1} \neq P_{2}$, terdapat $Q_{1}, Q_{2} \in m$ sehingga $P_{1}=Q_{1}$ dan $P_{2}=Q_{2}$.

3. Keterimpitan Titik ke Garis

Misalkan $\mathrm{P}$ sebarang titik dan 1 sebarang garis, $P \leftrightarrow l$ jika dan hanya jika $P \in l$.

Terdapat lima jenis kombinasi keterimpitan satu-lipatan yang mungkin dilakukan dengan origami yang membentuk operasi satu-lipatan yang dapat dilihat pada Error! Reference source not found. Kombinasi keterimpitan yang dapat dilakukan akan semakin bertambah jika banyaknya lipatan yang dilakukan dalam satu waktu juga bertambah sehingga dalam konstruksi origami Alperin-Lang dikenal adanya operasi dua-lipatan, tiga-lipatan, dst atau secara umum dikenal dengan operasi multi-lipatan.

\section{Metode Lill}

Pada 1867, Lill [17] menunjukkan bahwa jika diketahui suatu persamaan polinom berpeubah satu dengan derajat sebarang, maka akar-akarnya yang bernilai real bisa didapatkan dengan menggunakan suatu metode geometris.

Secara garis besar, penerapan Metode Lill ini terbagi menjadi dua langkah. Langkah pertama, dari koefsien-koefsien persamaan polinom dibangun diagram berbentuk lintasan yang disebut dengan Lintasan Lill. Persamaan polinom berderajat $\mathrm{n}$ akan membentuk Lintasan Lill yang memiliki $n+1$ segmen. Langkah kedua adalah membuat lintasan yang disebut Lintasan Solusi yang memiliki $n$ segmen yang berawal dan berakhir di titik yang sama dengan Lintasan Lill. Berikut ini penjelasannya. 


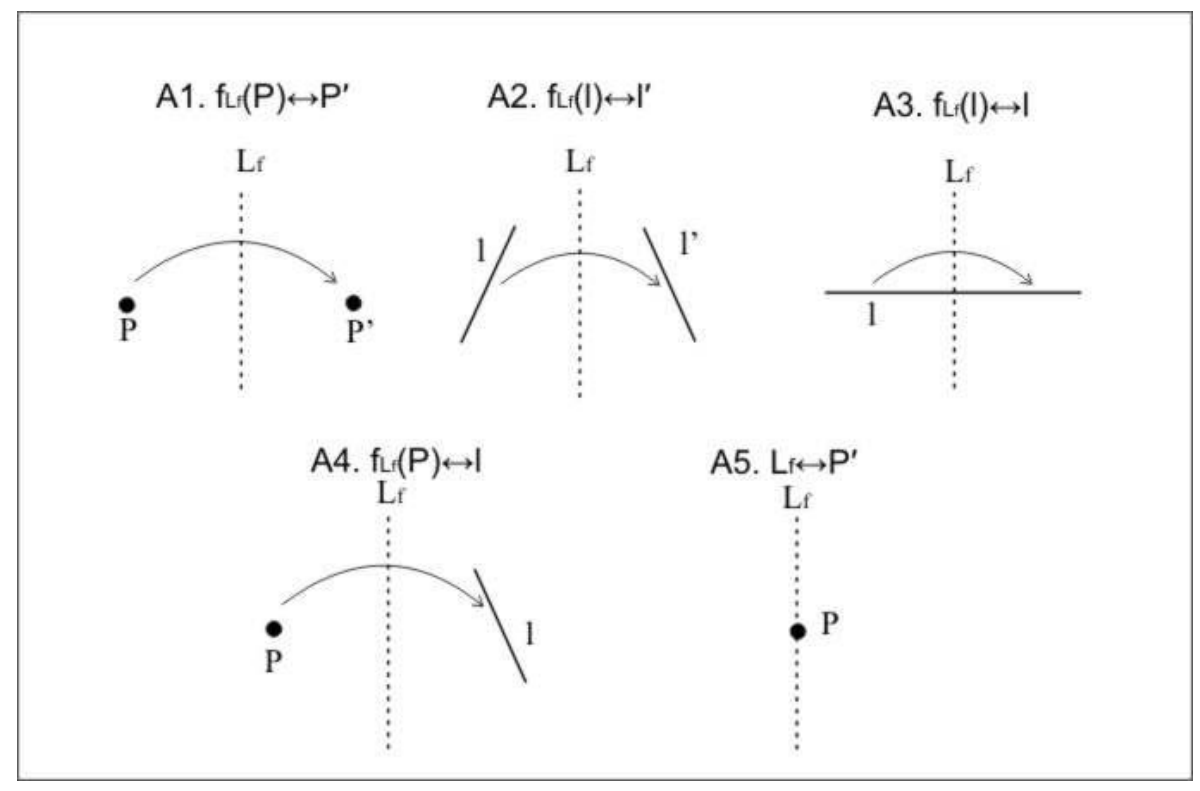

Gambar 2 Operasi Satu-Lipatan sebagai Kombinasi Keterimpitan Satu-Lipatan

Ambil sebarang polinom $f(x)=a_{n} x^{n}+\cdots+a_{1} x+a_{0}$ dengan koefisien real. Akan diperiksa apakah $f(x)$ memiliki akar real. Pertama-tama, tanpa mengurangi keumuman, misalkan koefisienkoefisien $f$ bernilai positif. Dibuat Lintasan Lill dengan menggunakan koefisien-koefisien $f(x)$ : dari titik awal $\mathrm{O}$, dibuat segmen pada sumbu x positif dengan panjang sama dengan koefisien $a_{n}$. Selanjutnya, berputar $90^{\circ}$ berlawanan arah jarum jam dan dibuat segmen baru yang panjangnya $a_{n-1}$. Kemudian, dibuat segmen selanjutnya dengan berputar $90^{\circ}$ berlawanan arah jarum jam dengan panjang segmen sama dengan $a_{(n-2)}$. Proses ini dilakukan berulang kali hingga berakhir di titik T setelah membuat segmen yang panjangnya $a_{0}$. Jika ada koefsien yang bernilai negatif, perputaran dilakukan searah jarum jam sehingga lintasan pada segmen tersebut dianggap bernilai negatif. Apabila ada koefisien bernilai nol, tetap berputar tetapi panjang segmennya nol.

Selanjutnya, akan dibuat Lintasan Solusi Lill. Lintasan ini juga dimulai dengan membuat segmen yang berawal di titik $O$ dan titik ujungnya berada di segmen Lintasan Lill yang panjangnya $a_{n-1}$, kemudian berbelok $90^{\circ}$ membentuk sudut siku-siku sehingga titik ujung segmen kedua berada pada segmen Lintasan Lill yang panjangnya $a_{n-2}$. Begitu seterusnya hingga lintasan tersebut akhirnya berhenti di titik T. Dapat dilihat bahwa Lintasan Solusi Lill memiliki $n$ sisi, sedangkan Lintasan Lill memiliki $n+1$ sisi. Contoh pembentukan lintasan Lill diperlihatkan pada Gambar 3 .

Teorema 1: Nilai tangen dari sudut $\theta$ yang terbentuk oleh Lintasan Lill dan Lintasan Solusi adalah solusi $f(x)=0$.

Bukti:

Tanpa mengurangi keumuman, misalkan semua koefsien dari $f(x)$ positif. Perhatikan bahwa sisi dari lintasan kedua adalah sisi miring dari barisan segitiga sebangun yang kaki-kakinya terletak pada lintasan pertama. Misalkan $y_{k}$ adalah panjang sisi yang berlawanan dengan sudut $\theta$ pada segitiga yang sisinya bertetangga dengan $\theta$ adalah ba-gian dari panjang $a_{k}$. Akan didapatkan

$$
\begin{aligned}
y_{n} & =(\tan \theta) a_{n}=-x a_{n} \\
y_{n-1} & =(\tan \theta)\left(a_{n-1}-\left(-x a_{n}\right)\right)=-x\left(a_{n-1}+x a_{n}\right) \\
y_{n-2} & =(\tan \theta)\left(a_{n-2}-\left(-x\left(a_{n-1}+x a_{n}\right)\right)\right)=-x\left(a_{n-2}+x\left(a_{n-1}+x a_{n}\right)\right) \\
& \vdots \\
y_{1} & =-x\left(a_{1}+x\left(a_{2}+\cdots+x\left(a_{n-2}+x\left(a_{n-1}+x a_{n}\right)\right) \cdots\right)\right) .
\end{aligned}
$$


Padahal diketahui $y_{1}=a_{0}$. Dengan melakukan substitusi nilai $y_{1}$, akan didapatkan

$$
\begin{aligned}
-a_{0} & =a_{n} x^{n}+\cdots+a_{1} x \\
0 & =a_{n} x^{n}+\cdots+a_{1} x+a_{0} \\
0 & =f(x) .
\end{aligned}
$$

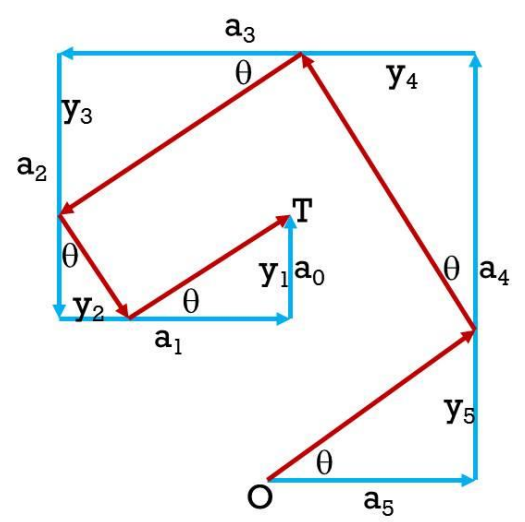

Gambar 3 Lintasan Lill dan Lintasan Solusi untuk Persamaan Derajat Lima dengan Semua Koefisien Positif

\section{Solusi Persamaan Kubik melalui Origami}

Kedua metode konstruksi origami yang telah dijabarkan tersebut dapat dipergu-nakan untuk mencari solusi persamaan polinom berderajat tiga atau yang dikenal dengan persamaan kubik. Untuk mencari solusi menggunakan konstruksi dari Alperin-Lang, diperlukan 'bantuan' berupa metode Lill untuk mencari solusi persamaan polinom.

\subsection{Solusi dengan Konstruksi Huzita-Justin}

Teorema 2: Misalkan terdapat titik $P=(a, b)$ dan $Q=(c, d)$ serta garis $m:=x=-a$ dan $n:=$ $y=-d$. Gradien $\mu$ dari garis lipatan $L_{f}$ yang memenuhi O6 adalah solusi persamaan kubik $d \mu^{3}+$ $c \mu^{2}+b \mu+a=0$.

Bukti:

Pertama-tama, dari $P$ dan $m$ dibuat parabola $C_{1}:=4 a x=(y-b)^{2}$, kemudian dari $Q$ dan $n$ dibuat parabola $C_{2}:=4 d y=(x-c)^{2}$. Gradien garis singgung dan titik singggung untuk parabola $C_{1}$ adalah:

$$
\begin{aligned}
4 a & =2(y-b) y^{\prime} \\
4 a & =2(y-b) \mu \\
y & =\left(\frac{2 a}{\mu}\right)+b .
\end{aligned}
$$

Substitusi titik singgung di parabola $C_{1}$, yaitu titik $\left(x_{1}, y_{1}\right)$ akan menghasilkan:

$$
y_{1}=\left(\frac{2 a}{\mu}\right)+b \text { dan } x_{1}=\frac{a}{\mu^{2}} .
$$

Gradien garis singgung dan titik singgung untuk parabola $C_{2}$ adalah: 


$$
\begin{aligned}
4 d y^{\prime} & =2(x-c) \\
4 d \mu & =2(x-c) \\
x & =2 d \mu+c
\end{aligned}
$$

Substitusi titik singgung di parabola $C_{2}$, yaitu titik $\left(x_{2}, y_{2}\right)$ akan menghasilkan:

$$
x_{2}=2 d \mu+c \text { dan } y_{2}=d \mu^{2} .
$$

Selanjutnya, gradien garis singgung $\mu$ juga dapat dicari menggunakan kedua titik yang telah diketahui $\left(x_{1}, y_{1}\right)$ dan $\left(x_{2}, y_{2}\right)$, yaitu

$$
\mu=\frac{y_{2}-y_{1}}{x_{2}-x_{1}}
$$

Substitusi persamaan (1) dan (2) ke dalam persamaan (3) akan menghasilkan

$$
\begin{aligned}
\mu & =\frac{d \mu^{2}-\left(\frac{2 a}{\mu}+b\right)}{2 d \mu+c-a \mu^{2}} \\
\mu\left(2 d \mu+c-a \mu^{2}\right) & =d \mu^{2}-\left(\frac{2 a}{\mu}+b\right) \\
d \mu^{3}+c \mu^{2}+b \mu+a & =0 .
\end{aligned}
$$

Sebagai contoh, pada Gambar 4, diperlihatkan cara mencari solusi persamaan kubik $x^{3}+3 x^{2}+$ $3 x+1=0$ menggunakan origami. Terlihat bahwa gradien garis $L_{f}, \mu=-1$ sesuai dengan solusi dari persamaan kubik tersebut jika dicari secara analitik.

Adapun persamaan kubik yang memiliki solusi jamak akan menyebabkan timbulnya lebih dari satu garis lipatan yang mampu memenuhi operasi O6 sebagaimana terlihat pada Gambar 5.

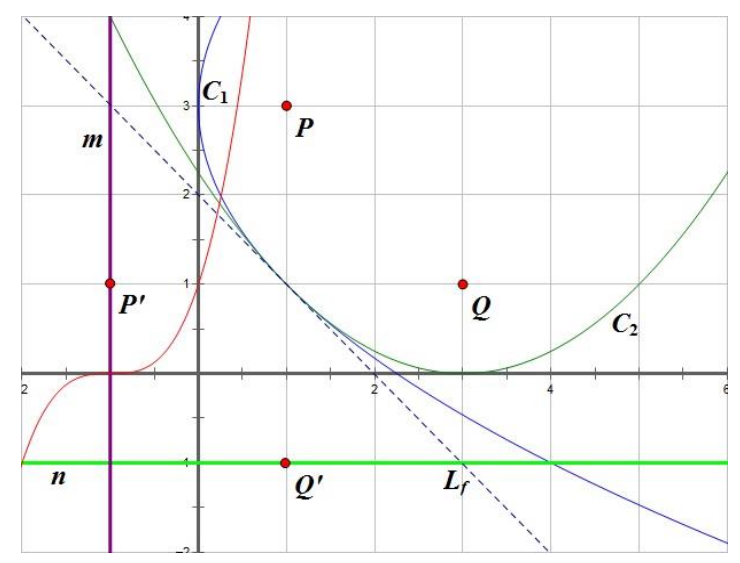

Gambar 4 Solusi Persamaan Kubik

$$
x^{3}+3 x^{2}+3 x+1=0
$$

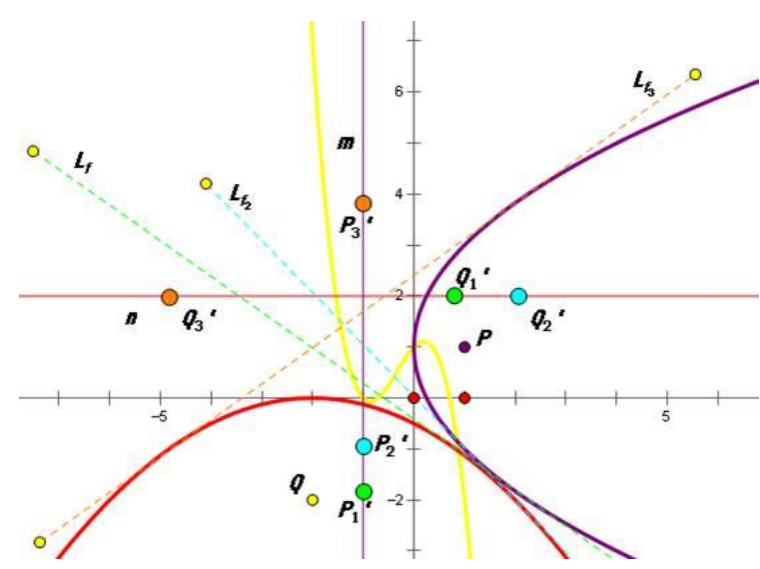

Gambar 5 Persamaan Kubik dengan Tiga Akar Real

\subsection{Solusi dengan Konstruksi Alperin-Lang}

Tanpa mengurangi kemumuman, ambil sebarang persamaan kubik $a_{3} x^{3}+a_{2} x^{2}+a_{1} x-a_{0}=0$ yang kofisien-koefisiennya bernilai positif. Dari nilai-nilai koefsien pada persamaan tersebut, dibuat garis $\mathrm{OA}, \mathrm{AB}, \mathrm{BC}$, dan $\mathrm{CT}$ yang panjangnya masing-masing $a_{3}, a_{2}, a_{1}$, dan $a_{0}$, seperti diilustrasikan oleh Gambar 6. 
Selanjutnya ditambahkan garis $L_{1}$ yang sejajar dengan $\mathrm{AB}$ dan berjarak sama dengan $\mathrm{OA}$. Ditambahkan juga garis $L_{2}$ yang sejajar dengan BC dan berjarak sama dengan CT. Menggunakan kombinasi 2 buah Keterimpitan A4, dapat dibuat garis lipatan $L_{f}$ sehingga $f\left(L_{f}(O)\right) \leftrightarrow L_{1}$ dan $f\left(L_{f}(T)\right) \leftrightarrow L_{2}$. Perpotongan $L_{f}$ dengan Lintasan Lill menghasilkan dua titik baru: X dan Y untuk membangun Lintasan solusi Lill. Jadi solusi persamaan kubik $a_{3} x^{3}+a_{2} x^{2}+a_{1} x-a_{0}=0$ adalah $x=-\tan \angle A O X=-\frac{A X}{O A}$.

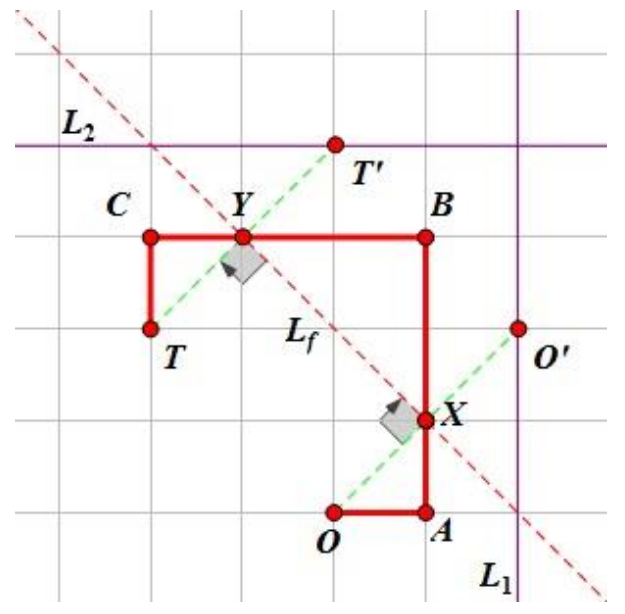

Gambar 6 Solusi Persamaan Kubik dengan Konstruksi Alperin-Lang

\section{Kesimpulan}

Dari perbandingan kedua metode tersebut, terlihat bahwa keduanya memberikan hasil yang cukup akurat untuk mendapatkan solusi persamaan kubik yang berupa bilangan bulat atau bilangan rasional. Namun, hingga saat ini, origami belum dapat dipergunakan untuk mengkonstruksi sebarang bilangan real, khususnya yang mengandung bilangan $\pi$ atau e. Keakuratan tersebut tentunya juga bergantung pada hal-hal teknis, seperti keterampilan pelipat kertas, jenis dan ukuran kertas, serta skala yang digunakan.

Dari langkah-langkah yang perlu dilakukan untuk mendapatkan solusi persamaan kubik, metode dengan konstruksi Huzita-Justin lebih sederhana, hanya perlu dua langkah: menempatkan titik P dan Q sesuai dengan konstanta koefisien dari persamaan kubik, lalu membuat lipatan yang memenuhi O6. Pencarian solusi dengan konstruksi Alpering-Lang lebih rumit karena harus membuat garis lintasan Lill terlebih dahulu, membuat garis-garis bantuan, lalu membuat lipatan yang membentuk lintasan solusi Lill.

Meskipun lebih rumit, konstruksi Alperin-Lang memiliki kelebihan dari konstruksi Huzita-Justin, yaitu dapat dipergunakan untuk mencari persamaan polinom berderajat lebih tinggi menggunakan susunan multi-lipatan.

\section{Referensi}

[1] T. Hull, Project origami: activities for exploring mathematics, AK Peters/CRC Press, 2006.

[2] E.D. Demaine and M.L. Demaine, Recent results in computational origami. Origami3: Third International Meeting of Origami Science, Mathematics and Education, 2002. pp. 3-16.

[3] W. Higginson and L. Colgan, Algebraic thinking through origami, Mathematics Teaching in the Middle School Vol 6, no. 6, 2001. p. 343. 
[4] R. Respitawulan, N. Afrianti, \& Y. Permanasari, Konstruksi Origami Sebagai Strategi Pembelajaran Matematika untuk Anak Usia Dini. Prosiding SNaPP: Sosial, Ekonomi dan Humaniora, 7(1), 2017,pp. 120-126.

[5] R. Haryanti \& M. Syukri, Peningkatan Aktivitas Pembelajaran Matematika Dengan Menggunakan Media Kertas Origami. Jurnal Pendidikan dan Pembelajaran, 3(6), 2014.

[6] N.T.A. Putra, I.M. Suarjana, \& I.G.N. Japa, Pengaruh Pendekatan Pendidikan Matematika Realistik Berbantuan Origami Terhadap Hasil Belajar Matematika Siswa Kelas V Sd Di Desa Les Kecamatan Tejakula Tahun Pelajaran 2013/2014. MIMBAR PGSD, 2(1). 2014.

[7] Y.G. Purbarini \& R.T. Purba, Pengembangan Buku Ajar Matematika Sekolah Dasar Berbasis Keterampilan Origami. Jurnal Pendidikan Indonesia, 3(5), 2017.

[8] M. Chiar \& M. Nasrun, Peningkatan Motivasi Belajar Matematika Siswa-Siswi Melalui Media Gambar Kertas Origami, Jurnal Pendidikan dan Pembelajaran, 2(1), 2013.

[9] S. Ningsih, Kecerdasan Visual Spasial Siswa SMP dalam Mengkonstruksi Rumus Pythagoras dengan Pembelajaran Berbasis Origami di Kelas VIII, MATHEdunesa, 1(3), 2014.

[10] L. Susanti \& A.H. Rosyidi, Pembelajaran Berbasis Origami untuk Meningkatkan Visualisasi Spasial dan Kemampuan Geometri Siswa SMP, Jurnal Mahasiswa Teknologi Pendidikan, 2(2), 2013.

[11] D. Wardhani, E.B. Irawan, \& C. Sa'dijah, Origami terhadap Kecerdasan Spasial Matematika Siswa, Jurnal Pendidikan: Teori, Penelitian, dan Pengembangan, 1(5), 2016. pp. 905-909.

[12] F.H. Badruzzaman dan Y. Karyana, Penggunaan Multimedia Dalam Proses Belajar Mengajar Kalkulus II, Jurnal Matematika Universitas Islam Bandung, Vol 5 No 1, 2005. pp.67-72.

[13] I.L. Nur'aini, E. Harahap, F.H. Badruzzaman, dan D. Darmawan. Pembelajaran Matematika Geometri Secara Realistis Dengan GeoGebra, Jurnal Matematika Universitas Islam Bandung, Vol 5 No 1, 2005. pp.67-72.

[14] T.C. Hull, Solving cubics with creases: the work of Beloch and Lill, The American Mathematical Monthly Vol 118, no. 4, 2011 pp. 307-315.

[15] R.J. Lang, Origami and geometric constructions, Self Published (1996 2003), 1996.

[16] R.C. Alperin and R.J. Lang, One-, two-, and multi-fold origami axioms, Origami 4, 2009. pp. 371-393.

[17] W.H. Bixby, Real Roots of Numerical Equations of Any Degree if Containing but One Variable, West Point, New York, 1879. 